\title{
Decreasing Coalbed Methane Formation Damage Using Microfoamed Drilling Fluid Stabilized by Silica Nanoparticles
}

\author{
Jihua Cai, ${ }^{1}$ Sui Gu, ${ }^{1,2}$ Fawen Wang, ${ }^{3}$ Xianyu Yang, \\ Ye Yue, ${ }^{1}$ Xiaoming $W u,{ }^{1}$ and V. F. Chixotkin ${ }^{1}$ \\ ${ }^{1}$ School of Engineering, China University of Geosciences, Wuhan 430074, China \\ ${ }^{2}$ Wuhan University of Engineering Science, Wuhan 430200, China \\ ${ }^{3}$ Hubei Institute of Urban Geological Engineering, Wuhan 430070, China \\ Correspondence should be addressed to Sui Gu; gusui2006@tom.com
}

Received 6 July 2015; Revised 18 December 2015; Accepted 22 December 2015

Academic Editor: Miguel A. Garcia

Copyright (C) 2016 Jihua Cai et al. This is an open access article distributed under the Creative Commons Attribution License, which permits unrestricted use, distribution, and reproduction in any medium, provided the original work is properly cited.

Coalbed methane (CBM) reservoirs in China are featured in remarkable nanosized pores below 200 nm, acknowledged natural cleats, and tectonic fractures. This paper discussed the possibility that a clay free microfoamed drilling fluid could be stabilized by silica nanoparticles (CFMDF-NP) so as to avoid formation damage of CBM drilling. In accordance with the experimental results of foaming capacity and foam stability test, basic drilling fluid performance appraisal, micromorphology observation, swelling test, and gas permeability test, the mechanism of the CFMDF-NP was discussed in this paper. The results indicated that, with 10-20 nm nano- $\mathrm{SiO}_{2}$, the foaming volume of traditional foamed drilling fluid could be improved by up to $50 \%$ and an increased half-life period by up to $200 \%$. Chemically treated nano- $\mathrm{SiO}_{2}$ dispersions functioned as a foam stabilizer and a foaming agent as well. The CFMDF-NP had controllable density $\left(0.7 \sim 1 \mathrm{~g} / \mathrm{cm}^{3}\right)$ and excellent rheological and sealing properties, which could satisfy the drilling requirements of the low pressure coal seams. With $5-8 \mathrm{~mm}$ slicing on the contaminated side of coal cores, the contaminated zone could be removed and the recovery rate of gas permeability could reach up to 70\%. The CFMDF-NP laid good technical foundation to decrease formation damage of CBM reservoir.

\section{Introduction}

(1) Pore Structure Characteristics of Coalbed Methane (CBM) Reservoir. The pore structure of coal has attracted extensive attention, which not only directly determines the gas adsorption and desorption ability of coal [1-3], but also affects the interaction between pores and drilling fluid. According to the IUPAC classification [4-6] of coal pore size, the pore structures of coal are divided into micropores $(<2 \mathrm{~nm})$, mesopores $(2 \mathrm{~nm}-50 \mathrm{~nm})$, and macropores $(>50 \mathrm{~nm})$. Nanosized pores including micropores, mesopores, and macropores below $200 \mathrm{~nm}$ are widely found in the coal matrix from widespread coals samples as well as acknowledged natural cleats and tectonic fractures [1-3, 7-11]. For example, mesopores and micropores in the CBM reservoirs from San Juan basin, Black Warrior basin, Piceance basin in USA, and Qinshui basin in China have a proportion above $75 \%[9,12]$.
(2) Formation Pressure Characteristics of CBM Reservoir. On the other hand, the pressure gradient of CBM reservoirs ranges from 3.68 to $9.72 \mathrm{kPa} / 100 \mathrm{~m}$ and averages to be $6.68 \mathrm{kPa} / 100 \mathrm{~m}$, based on the testing parameters from $31 \mathrm{CBM}$ testing wells in Qinshui Basin, Shanxi, China $[9,13]$. It indicated a rather low pressure gradient level. Encountered with commonly used water, bentonite mud, and cement slurry, it might easily result in lost circulation and formation damage induced by hydraulic pressure differential (the differential between static hydraulic pressure of drilling fluid or cement slurry and formation pressure).

(3) Formation Damage Mechanisms Caused by Commonly Used Drilling Fluids in CBM Drilling. Drilling fluid interacts with coal seams directly during the exploitation of CBM resources. Low mechanical strength of coal often leads to structural collapse and crush and produced formation damage around the wellbore $[14,15]$ as well. Therefore, drilling 
fluid is required for ensuring borehole stability of coal seams with natural cleats, tectonic fractures, and nanosized pores and reducing formation damage as much as possible [16-19].

During CBM drilling, although water is widely used, its cuttings-carrying capacity is poor, which may easily cause borehole collapse. Plenty of drilling practices have shown that it can only be used in stable coal seams with relatively simple structure. Moreover, it may cause formation damage to coal seams with a high content of clay minerals. Taking the 3\# coal seam in Jincheng, Shanxi, China, as an example, it had $8 \%$ clay minerals on average $[13,20]$. Moreover, it is ascertained that gas flow into the borehole from coal seams is through natural cleats and tectonic fractures while the cleats porosity occupies 1-2\% of the total porosity in the coal rocks. Coal matrix has strong capability to absorb liquid and gas as it contains plenty of organic humic molecules. Therefore, the slight expansion of coal matrix may bring the substantial decrease in cleats' gas permeability. Coal sample obtained from 1st test well of Jincheng in contact with deionized water experienced a decrease in gas permeability from $0.47 \mathrm{mD}$ to $0.33 \mathrm{mD}$. A decreasing ratio of $29.78 \%$ of the gas permeability was observed [12]. Gentzis et al. [21] also found that coal fines (cuttings) appearing in simulated drilling of a coal seam with brine were severely harmful to the cleats. The near wellbore permeability was reduced by $87.5 \%$.

Bentonite mud is frequently used to stabilize coal seams. It is accepted that the fractures in CBM reservoir are featured in "being flat, straight, and wide" for their featured face cleats and butt cleats. Where the particles (such as bentonite, lost circulation materials, and cuttings) in the drilling fluid match with the width or diameter of the cleats or fractures, they will invade into the deep space of the reservoir along with the filtrate until they are deposited and lose the mobility. Coal samples from Liulin, Shanxi, China, went through a loss of permeability that varied in the range of $1.13-81.42 \%$, depending on the original permeability and the matching relationship between the particles size and the width or diameter of cleat or fracture [12].

Furthermore, to increase borehole stability and improve solids transport capability, polymer solution is a substitution to bentonite mud. As mentioned above, coal has rather powerful adsorption capability. The polymers can be absorbed or plugged into the fractures and pores of coal rocks, resulting in the decline of gas permeability. Zhao et al. [12] found that the gas permeability of the coal sample collected from Liulin, Shanxi, China, decreased from $3.17 \mathrm{mD}$ to $1.86 \mathrm{mD}$ when it contacted $0.1 \%$ partially hydrolyzed polyacrylamide (PHP) solution.

Air drilling is featured in high efficiency and less formation damage in stable and hard coal seams in United States and China. However, it is difficult to directly apply air drilling to the unstable or loose coal seams [22]. Therefore, engineered and powerful drilling fluid with low formation damage is necessary to handle the problem of borehole stability and reservoir protection.

(4) Examples of Low Damage Drilling Fluids in CBM Drilling. Barr [17] introduced the guideline to optimize drilling fluids for CBM reservoirs, including reservoir analysis, coal rank analysis, soak and roll test, hot roll analysis on shale samples, methylene blue test method, production water analysis, rheology of drilling fluid with both production water and fresh water, and capillary suction time analysis. Baltoiu et al. [16] developed a unique "matting" drilling fluid by exploiting the strong surface electrical charge of the coal, which could not only maintain borehole stability but also minimize fluid loss. Two boreholes with the length over $1000 \mathrm{~m}$, drilled with the unique drilling fluid system, showed exceptional stability in Mannville coal seams of Central Alberta, Canada. Gentzis et al. [21] found that a thin mud cake could be made using two fluid loss control additives of FLC 2000 and Q-stop, and a small pressure drop was sufficient to remove the mud cake. Apart from a little fluid loss, no borehole instability problem was found in two boreholes with the length of $953 \mathrm{~m}$ and $1400 \mathrm{~m}$ in the deep Mannville coals in Alberta, Canada. Zheng et al. [23] developed fuzzyball working fluid suitable for low-pressure leakage coal seams, which could plug leaking passages of different size simultaneously without any impact on normal operation, and the formation damage could be reduced effectively. It seems that physical plugging is an effective and frequently used method to decrease water invasion into reservoirs and to avoid borehole instability or formation damage in oil and gas drilling. The physically plugged silica nanoparticles (nano$\mathrm{SiO}_{2}$ ) are capable of improving the shale wellbore stability upon Gurpi shale in Iran, Atoka shale in Golf of Mexico, and Mancos shale in North Texas, USA [24-26].

Foam has been utilized as drilling fluid to achieve underbalanced drilling in the low pressure formation for several decades [27-29]. For instance, recycled microfoamed drilling fluid can help to solve lost circulation and formation damage in the low pressure formation. It does not require special foam generator if the flow or mixing conditions are complete [30] and present good cuttings-carrying performance in horizontal wells [31].

Here, we propose clay free microfoamed drilling fluid stabilized by nano-SiO 2 (CFMDF-NP) to mitigate formation damage to coal seams featured with natural cleats, tectonic fractures, nanosized pores, and low formation pressure in China. It can invade into the CBM reservoir with limited depth (below $10 \mathrm{~mm}$ ). Based on foaming capability and foam stability appraisal, basic drilling fluid performance test, micromorphology observation, swelling test with man-made coal cores, and gas permeability test upon original coal rocks, the mechanism of the CFMDF-NP for reducing formation damage to CBM reservoir was derived.

\section{Materials and Methods}

2.1. Materials. Nano- $\mathrm{SiO}_{2}$ dispersion was bought from Hangzhou Wanjing New Materials Co., Ltd., in China. It was milk white, with the silica's concentration of $30 \%$. Its diameter varied from $10 \mathrm{~nm}$ to $20 \mathrm{~nm}$, as shown in Figure 1: transmission electron microscopy (TEM) picture.

Foaming agents such as sodium dodecyl benzene sulfonate (ABS) and lauryl sodium sulfate $\left(\mathrm{K}_{12}\right)$ were chemically pure and bought from local chemical stores. Foam stabilizer 
TABle 1: Composition of coal samples from $3 \#$ coal seam in Jincheng, Shanxi, China.

\begin{tabular}{lcccc}
\hline Amorphous component & Calcite & Dolomite & Kaolinite & Quartz \\
\hline $59 \%$ & $20 \%$ & $15 \%$ & $5 \%$ & $1 \%$ \\
\hline
\end{tabular}

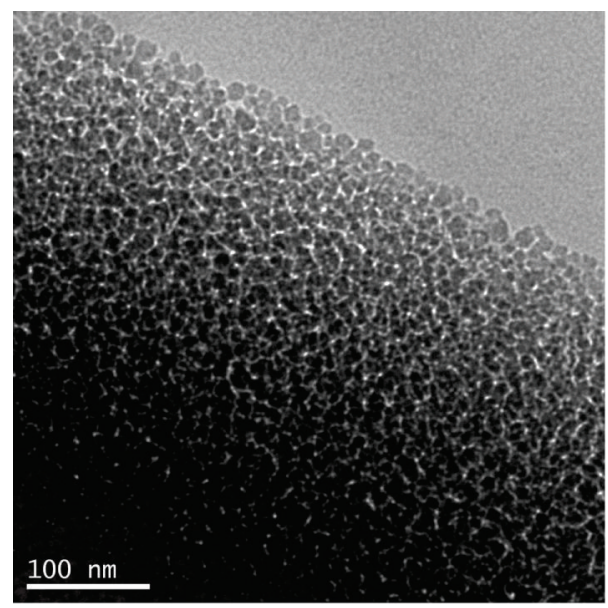

Figure 1: TEM picture of nano- $\mathrm{SiO}_{2}$.

such as xanthan gum (XC) and carboxymethyl cellulose (CMC) was chemically pure and bought from local chemical stores, which also acted as viscosifier to offer the basic rheological properties of the foamed drilling fluid. Filtration additive such as modified starch (DFD) and polyanionic cellulose (PAC) was chemically pure and bought from local chemical stores.

Coal samples were collected from $3 \#$ coal seam in Jincheng, China. Its composition was shown in Table 1 and porosity was $10 \%$. Typical interpretation with Image J for the original scanning electron microscope (SEM) pictures of the varied sections (Figure 2) presented the pore distribution pattern in the matrix of coal rocks from $3 \#$ coal seam in Jincheng, China, varying from $25 \mathrm{~nm}$ to $439 \mathrm{~nm}$. Based on the statistical data analysis, the pores below $200 \mathrm{~nm}$ accounted for not less than $80 \%$.

SC-50B core rig was used to get cores with the diameter of $25 \mathrm{~mm}$ for gas permeability test. Moreover, $4.6 \mathrm{~g}$ coal powder of 140-160 meshes, $0.4 \mathrm{~g}$ bentonite, moderate dosage of sodium silicate, and $\mathrm{CaCl}_{2}$ solution were mixed together and poured into a core pressing machine for 20 minutes at $15 \mathrm{MPa}$. These man-made coal cores were prepared for swelling test, with the diameter of $25 \mathrm{~mm}$ and the height of $9.2 \mathrm{~mm}$.

2.2. Apparatus. Apparatus such as FA-1004 electronic scale, GJD-B12K high-speed mixer, ZNN-D6 rotary viscometer, ZNS-5A filter press, Zhongxing101 electric air blowing dryer, JHP core pressing machine, ZNP-1 swelling capacity tester, SC-50B core rig, QM-1 core rock cutting and sharpening machine, JHGP intelligent gas permeability tester, JHCF core flowing tester, and metallographic electron microscope were used in the experiments.

\subsection{Method}

2.3.1. Effect of $\mathrm{Nano}-\mathrm{SiO}_{2}$ on Foaming Capacity and Foam Stability of Foamed Drilling Fluid. Four types of foamed drilling fluid formulas were screened out based on a few tests:

$$
\begin{aligned}
& \text { 1\#: water + 0.3\% ABS + 0.3\% CMC; } \\
& \text { 2\#: water + 0.3\% } \mathrm{ABS}+0.3 \% \mathrm{XC} \text {; } \\
& \text { 3\#: water + } 0.3 \% \mathrm{~K}_{12}+0.3 \% \mathrm{CMC} \text {; } \\
& \text { 4\#: water }+0.3 \% \mathrm{~K}_{12}+0.3 \% \mathrm{XC}
\end{aligned}
$$

Water, foam stabilizer, $0 \sim 0.125 \%$ nano- $\mathrm{SiO}_{2}$, and foaming agent were mixed successively for $60 \mathrm{~s}$ at $1000 \mathrm{r} / \mathrm{min}$. Two samples were prepared for each formula. Foaming capacity (foaming volume, $\mathrm{mL}$ ) and foam stability (half-life period, min) were evaluated separately. The results were shown in Table 2 and Figure 3.

\subsubsection{Effect of Nano-SiO $\mathrm{O}_{2}$ on Foam Stability of Microfoamed} Drilling Fluid. The half-life period of microfoamed drilling fluid spanned from several hours to tens of hours, which might result in error in the testing process. Undoubtedly, the more the broken foam, the higher the density of microfoamed drilling fluid. Therefore, the foam stability was evaluated by testing the density change rate of the foamed drilling fluid based on the original density. Two types of microfoamed drilling fluids were developed, including the low viscosity clay free microfoamed drilling fluid (LV-CFMDF) and LVCFMDF plus $2 \%$ nano-SiO 2 (LV-CFMDF-NP), to find out the difference in foam stability with or without the nano- $\mathrm{SiO}_{2}$. The formula was listed as follows:

$$
\begin{aligned}
& \text { LV-CFMDF: water }+0.1 \% \text { CMC }+0.2 \% \text { DFD }+ \\
& 0.005 \% \mathrm{~K}_{12}+0.2 \% \mathrm{XC}+0.1 \% \text { PAC. } \\
& \text { LV-CFMDF-NP: LV-CFMDF + } 2 \% \text { nano- } \mathrm{SiO}_{2} .
\end{aligned}
$$

In intensifying the bubbles in the microfoamed drilling fluid, the presence of polymers like XC, CMC, PAC, and DFD also offered the basic rheological, filtration control properties of the drilling fluid, which ensured the cuttings could be brought to the surface and decrease the fluid loss in the CBM reservoirs. The result of foam stability appraisal based on the change rate of density was shown in Figure 4.

2.3.3. Basic Parameters and Micromorphology. Successively, the basic parameters such as density, apparent viscosity (AV), plastic viscosity (PV), yield point (YP), and fluid loss (FL) were evaluated, as shown in Table 3. Besides the LV-CFMDF$\mathrm{NP}$ as mentioned in Section 2.3.2, the high viscosity clay free microfoamed drilling fluid stabilized by nano- $\mathrm{SiO}_{2}(\mathrm{HV}-$ CFMDF-NP) was also proposed here.

HV-CFMDF-NP is composed of water $+0.2 \% \mathrm{CMC}+$ $0.5 \% \mathrm{DFD}+0.01 \% \mathrm{~K}_{12}+0.3 \% \mathrm{XC}+0.2 \% \mathrm{PAC}+2 \%$ nano$\mathrm{SiO}_{2}$.

The basic performance and the micromorphology of the microfoamed drilling fluid were shown in Table 3 and Figure 5, respectively. 


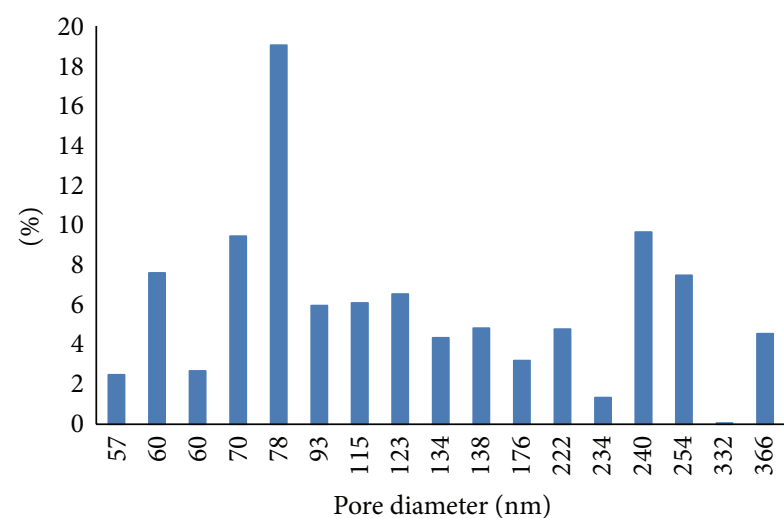

(a)

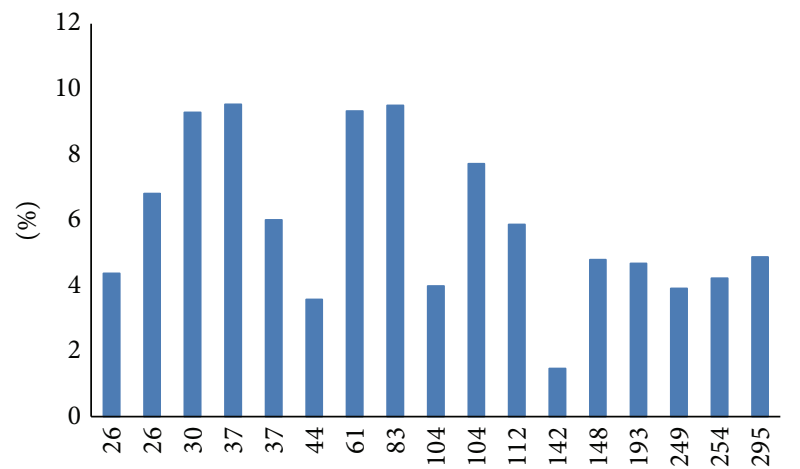

Pore diameter $(\mathrm{nm})$

(c)

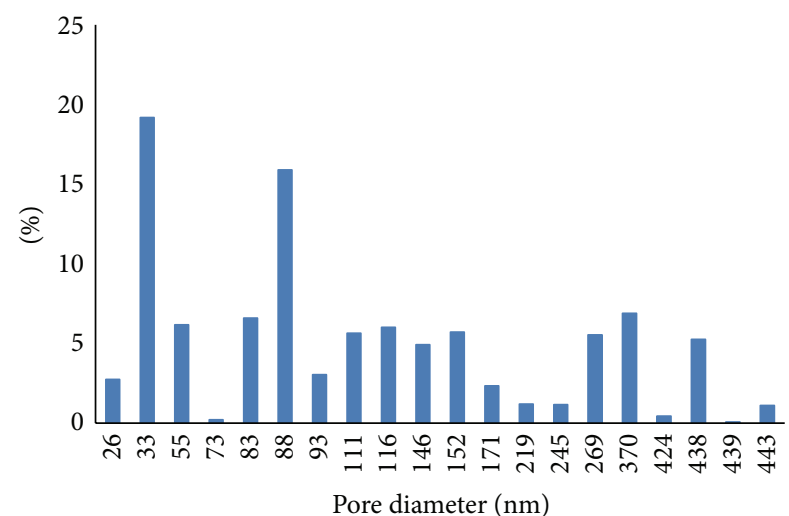

(b)

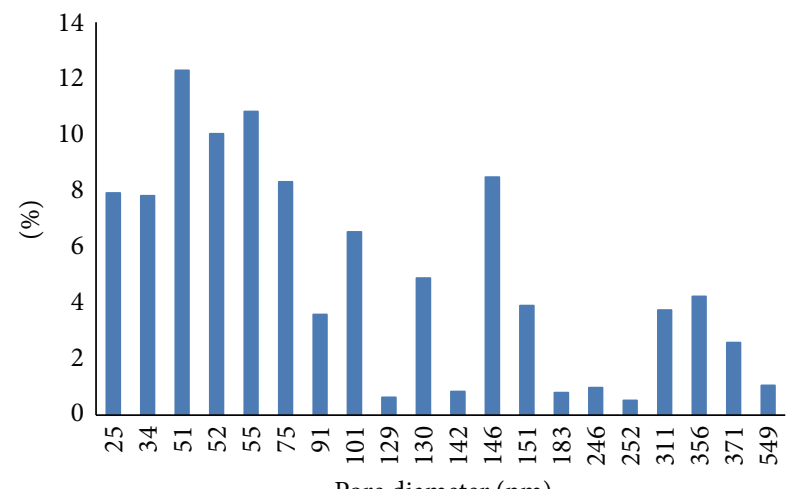

Pore diameter $(\mathrm{nm})$

(d)

FIGURE 2: Pore diameter distribution patterns interpreted by Image J software for original SEM pictures of the coal rocks from 3\# coal seam in Jincheng, Shanxi, China.

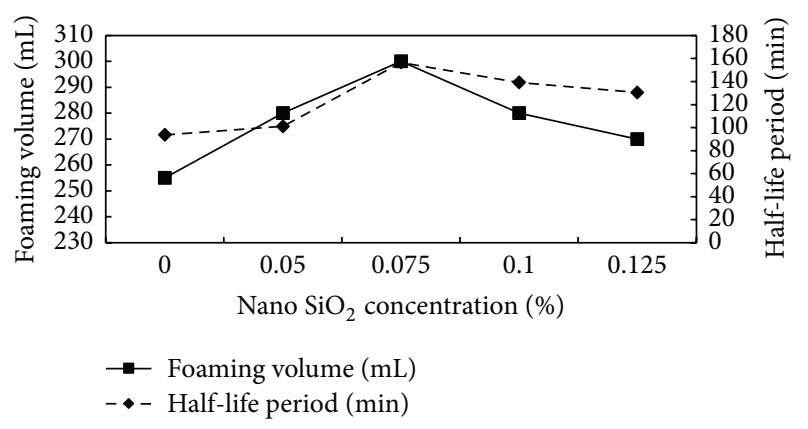

FIGURE 3: Influence of nano- $\mathrm{SiO}_{2}$ on foam capacity and stability of foamed drilling fluid (formula 2\#).

2.3.4. Swelling Test. As mentioned above, coal samples from $3 \#$ and 15\# coal seam in Jincheng, Shanxi, China, had an average clay mineral content over $8 \%$ [13]. Therefore, $8 \%$ sodium bentonite was added into the man-made coal sample to evaluate the swelling increment of coal rocks in contact with the HV-CFMDF-NP. To get better comparison effect, fresh water, $3 \%$ bentonite mud, and 3\% potassium chloride $(\mathrm{KCl})$ solution were examined together. The swelling

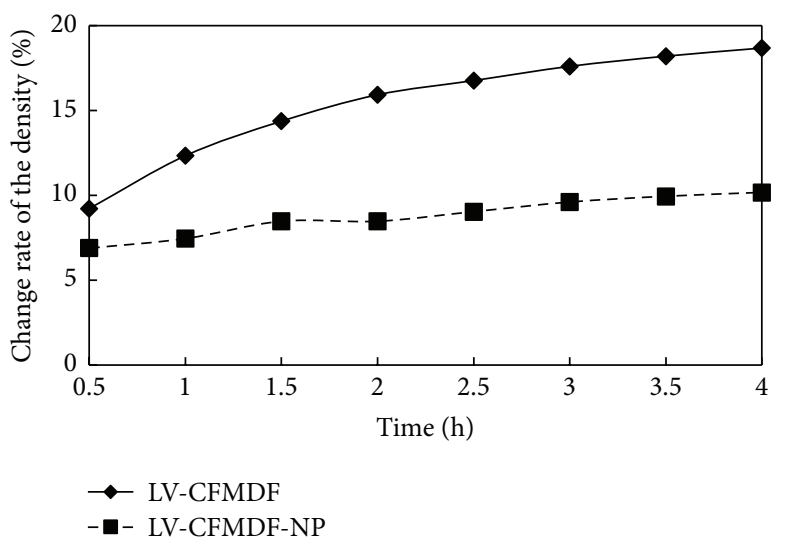

FIGURE 4: Comparison of the change rate of the density of microfoamed drilling fluid.

increment $(\mathrm{mm})$ was checked every half an hour. The result was shown in Figure 6.

2.3.5. Gas Permeability Appraisal. The permeability of coal rocks is the most important parameter, which affects the production of CBM wells. Therefore, the permeability of 
TABLE 2: Foaming volume and half-life period data of foamed drilling fluid with different formula in presence of nano-SiO${ }_{2}$.

\begin{tabular}{|c|c|c|c|c|c|}
\hline Formula number & Nano-SiO ${ }_{2}(\%)$ & $\begin{array}{c}\text { Foaming } \\
\text { volume }(\mathrm{ml})\end{array}$ & $\begin{array}{c}\text { Growth rate of } \\
\text { foaming volume } \\
(\%)\end{array}$ & $\begin{array}{l}\text { Half-life period } \\
\qquad(\mathrm{min})\end{array}$ & $\begin{array}{c}\text { Growth rate of } \\
\text { foam stability } \\
(\%)\end{array}$ \\
\hline \multirow{5}{*}{$1 \#$} & 0 & 325 & 0.00 & 14.07 & 0.00 \\
\hline & 0.05 & 350 & 7.69 & 16.00 & 13.72 \\
\hline & 0.075 & 350 & 7.69 & 18.67 & 32.69 \\
\hline & 0.1 & 340 & 4.62 & 16.17 & 14.93 \\
\hline & 0.125 & 330 & 1.54 & 14.97 & 6.40 \\
\hline \multirow{5}{*}{$2 \#$} & 0 & 255 & 0.00 & 93.68 & 0.00 \\
\hline & 0.05 & 280 & 9.80 & 101.07 & 7.89 \\
\hline & 0.075 & 300 & 17.65 & 156.57 & 67.13 \\
\hline & 0.1 & 280 & 9.80 & 139.18 & 48.57 \\
\hline & 0.125 & 270 & 5.88 & 130.50 & 39.30 \\
\hline \multirow{5}{*}{$3 \#$} & 0 & 275 & 0.00 & 20.97 & 0.00 \\
\hline & 0.05 & 305 & 10.91 & 29.48 & 40.58 \\
\hline & 0.075 & 340 & 23.64 & 37.50 & 78.83 \\
\hline & 0.1 & 285 & 3.64 & 27.43 & 30.81 \\
\hline & 0.125 & 300 & 9.09 & 26.93 & 28.42 \\
\hline \multirow{5}{*}{$4 \#$} & 0 & 150 & 0.00 & 63.13 & 0.00 \\
\hline & 0.05 & 170 & 13.33 & 91.74 & 45.32 \\
\hline & 0.075 & 235 & 56.67 & 200.48 & 217.57 \\
\hline & 0.1 & 230 & 53.33 & 156.90 & 148.53 \\
\hline & 0.125 & 220 & 46.67 & 140.40 & 122.40 \\
\hline
\end{tabular}

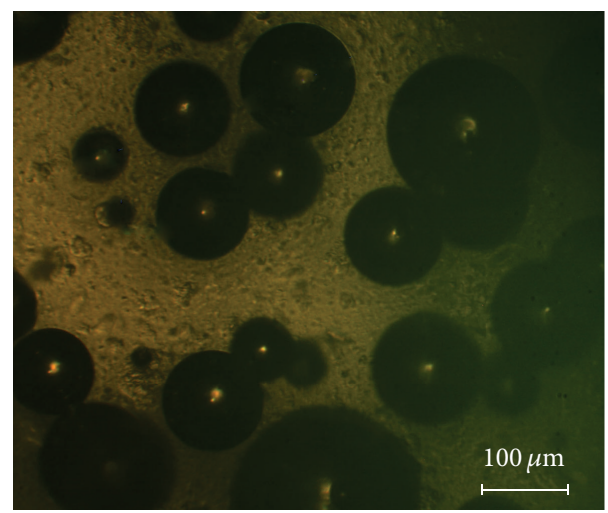

FIGURE 5: Micromorphology of HV-CFMDF-NP magnified by 50 times.

the original coal rocks in contact with varied working fluids can be used to evaluate their reservoir protection effect. The tests were carried out in the following steps.

Three coal cores were sampled by drilling and numbered as $1-3 \#$. The forward gas $\left(\mathrm{N}_{2}\right.$, the same below) permeability was obtained through the JHGP intelligent gas permeability tester at ambient temperature and denoted as $K_{0}$. The coal core was contaminated at reverse direction by the $\mathrm{HV}$ CFMDF-NP in the JHCF core flowing tester at $2 \mathrm{MPa}$ confining pressure and $1 \mathrm{MPa}$ axle pressure. The gas permeability at forward direction was tested and denoted as $K_{1}$. The contaminated side of the coal core was sliced by $5-8 \mathrm{~mm}$ and the gas permeability at forward direction was tested and denoted as $K_{2}$.

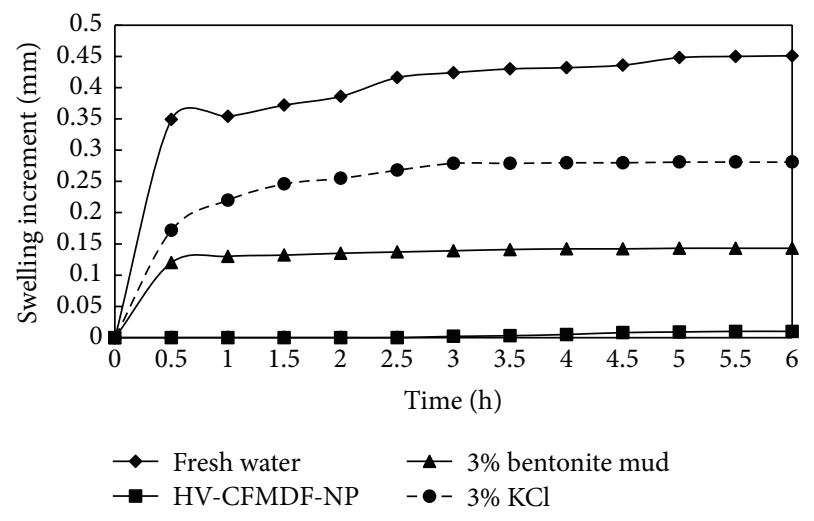

FIGURE 6: Influence curves of different drilling fluids on the expansibility of coal samples.

As for coal core 4-5\#, the procedure was similar, except the difference that the HV-CFMDF-NP was substituted by $3 \%$ $\mathrm{KCl}$ solution. In the test with $3 \% \mathrm{KCl}$ solution, the fluid loss at the other side of the coal core was also recorded for its low viscosity. The results of gas permeability tests were shown in Figure 7 and Table 4.

\section{Results and Discussion}

3.1. Effect of Nano-SiO $\mathrm{N}_{2}$ on Foaming Capacity and Foam Stability of Foamed Drilling Fluid. Similar to each formula, better foaming and stable effect were observed when the nano- $\mathrm{SiO}_{2}$ 's concentration ranged from 0.05 to $0.1 \%$ and the optimal dosage of nano- $\mathrm{SiO}_{2}$ was $0.075 \%$, as shown in 
TABLE 3: Basic properties of microfoamed drilling fluid containing NPs.

\begin{tabular}{|c|c|c|c|c|c|c|}
\hline Drilling fluid type & $\rho\left(\mathrm{g} / \mathrm{cm}^{3}\right)$ & $\mathrm{AV}(\mathrm{mPa} \cdot \mathrm{s})$ & $\mathrm{PV}(\mathrm{mPa} \cdot \mathrm{s})$ & $\mathrm{YP}(\mathrm{Pa})$ & $\mathrm{Gel}(\mathrm{Pa} / \mathrm{Pa})$ & $\mathrm{FL}(\mathrm{mL})$ \\
\hline LV-CFMDF-NP & 0.885 & 19.5 & 15 & 4.5 & $0.4 / 0.5$ & - \\
\hline HV-CFMDF-NP & 0.872 & 37.5 & 20.5 & 17 & $2.5 / 2.75$ & - \\
\hline
\end{tabular}

Note: $\rho$ : density, AV: apparent viscosity, PV: plastic viscosity, YP: yield point, Gel: gel strength, and FL: API fluid loss.

TABLE 4: Gas permeability test results of original coal core samples.

\begin{tabular}{|c|c|c|c|c|c|c|c|}
\hline No. & $\begin{array}{l}\text { Length } \\
(\mathrm{mm})\end{array}$ & $\begin{array}{c}\text { Confining } \\
\text { pressure } \\
(\mathrm{MPa})\end{array}$ & $\begin{array}{c}K_{0} \\
(\mathrm{mD})\end{array}$ & $\begin{array}{c}K_{1} \\
(\mathrm{mD})\end{array}$ & $\begin{array}{r}\Delta K_{1} \\
(\%)\end{array}$ & $\begin{array}{c}K_{2} \\
(\mathrm{mD})\end{array}$ & $\begin{array}{r}\Delta K_{2} \\
(\%)\end{array}$ \\
\hline \multirow{4}{*}{$1 \#$} & \multirow{4}{*}{19.28} & 0.35 & 8.19 & 2.29 & 72.00 & 6.61 & 80.78 \\
\hline & & 0.38 & 8.22 & 2.23 & 72.92 & 7.38 & 89.76 \\
\hline & & 0.40 & 8.37 & 2.23 & 73.39 & 7.22 & 86.34 \\
\hline & & & 8.26 & 2.25 & 72.77 & 7.07 & 85.63 \\
\hline \multirow{4}{*}{$2 \#$} & \multirow{4}{*}{29.68} & 0.35 & 5.45 & 2.77 & 49.13 & 4.43 & 81.18 \\
\hline & & 0.38 & 5.41 & 2.69 & 50.24 & 4.19 & 77.55 \\
\hline & & 0.40 & 5.44 & 2.67 & 50.87 & 3.88 & 71.29 \\
\hline & & & 5.43 & 2.71 & 50.08 & 4.16 & 76.68 \\
\hline \multirow{4}{*}{$3 \#$} & \multirow{4}{*}{29.10} & 0.35 & 2.32 & 1.39 & 40.00 & 2.03 & 87.81 \\
\hline & & 0.38 & 2.28 & 1.34 & 40.91 & 1.92 & 84.56 \\
\hline & & 0.40 & 2.25 & 1.32 & 41.24 & 1.92 & 85.53 \\
\hline & & & 2.28 & 1.35 & 40.72 & 1.96 & 85.97 \\
\hline \multirow{4}{*}{$4 \#$} & \multirow{4}{*}{25.25} & 0.35 & 10.59 & 5.63 & 46.84 & $*$ & * \\
\hline & & 0.38 & 10.32 & 5.61 & 45.64 & * & $*$ \\
\hline & & 0.40 & 10.45 & 5.73 & 45.17 & * & $*$ \\
\hline & & & 10.46 & 5.66 & 45.89 & * & * \\
\hline \multirow{4}{*}{ 5\# } & \multirow{4}{*}{21.53} & 0.35 & 2.86 & 1.42 & 50.35 & * & $*$ \\
\hline & & 0.38 & 2.74 & 1.38 & 49.64 & * & $*$ \\
\hline & & 0.40 & 2.78 & 1.30 & 53.24 & * & * \\
\hline & & & 2.79 & 1.37 & 50.90 & * & $*$ \\
\hline
\end{tabular}

Note: (1) the confining pressure was $0.9 \mathrm{MPa}$ and the downstream pressure (outlet pressure) was $0.1 \mathrm{MPa}$ (1 atmospheric pressure). (2) Gas permeability reducing rate was calculated with $\Delta K_{1}=\left[\left(K_{0}-K_{1}\right) / K_{0}\right] \times 100 \%$. (3) Gas permeability recovery rate was calculated with $\Delta K_{2}=K_{2} / K_{0} \times 100 \%$. (4) *: the coal core was totally contaminated, so it was not necessary to slice it.

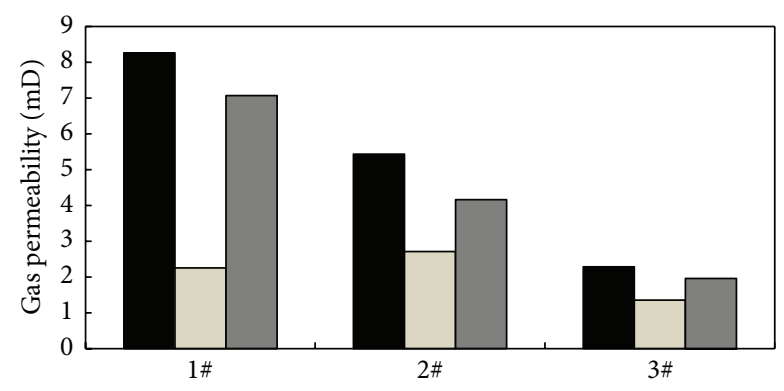

Number of coal rocks

Original

$\square$ Contaminated for $2 \mathrm{~h}$

Sliced by $5-8 \mathrm{~mm}$

FIGURE 7: Comparison of the average gas permeability of coal cores during various testing stage.

Table 2. With formula 2\# as an example, its graphic results were shown in Figure 3.
In formula 2\#, the foaming capability of foamed drilling fluid could be improved by up to $17.65 \%$ and its half-life period could be increased by up to $67.13 \%$. The highest growth rate of foaming volume and half-life period appeared in formula 4\#, with the corresponding value of $56.67 \%$ and $217.57 \%$, respectively. Therefore, unlike conventional foam stabilizers, chemically treated nano- $\mathrm{SiO}_{2}$ dispersions functioned not only as a foam stabilizer but also as a foaming agent. Conventional foam stabilizers such as XC and CMC improved the stability of foam and decreased the foaming volume simultaneously.

Moreover, in the presence of stabilizer like XC (in formulas $2 \#$ and 4\#), the foamed drilling fluid had less foaming volume and longer half-life period compared to CMC. Its half-life period reached up to 2.5-3.0 hours which might satisfy the requirements of CBM drilling. It indicated that $\mathrm{XC}$ was superior to $\mathrm{CMC}$ for its higher molecular weight $\left(5 \times 10^{6}\right)$ and better viscosifying capability. More elastic and deformable foam membranes could be formed, resulting in less foaming volume and better stability of the drilling fluid. 
3.2. Effect of Nano-SiO $\mathrm{O}_{2}$ on Foam Stability of Microfoamed Drilling Fluid. For the microfoamed drilling fluid prepared with the same formula, the foaming capacity and foam density varied from each other, depending on mixing conditions. For example, longer mixing time and faster mixing speed always brought higher foaming volume, lower mud density, and smaller bubble size. That is to say, these parameters could be adjusted to match with the coal geology pattern as necessary. For convenience, the mixing time in the subsequent tests was set as 20 minutes and the mixing speed was set as $3000 \mathrm{r} / \mathrm{min}$ uniformly.

Figure 4 indicated that both the LV-CFMDF and the LV-CFMDF-NP experienced an increase of density in 4 hours. The LV-CFMDF's density had higher growth rate as $18.68 \%$ in the absence of nano- $\mathrm{SiO}_{2}$. The growth rate of the density of the LV-CFMDF-NP was only $10.17 \%$. A differential decreasing rate of $8 \%$ was observed without or with nano$\mathrm{SiO}_{2}$. This confirmed the capability of nano-SiO${ }_{2}$ improved the foam stability of microfoamed drilling fluid.

3.3. Basic Parameters and Micromorphology. It could be seen from Table 3 that the density and rheological parameters of the CFMDF-NP were fine. The selection of the LV-CFMDFNP or the HV-CFMDF-NP could be decided by the coal geology pattern such as mechanical strength and integrity of the coal rocks. The high viscosity system had better borehole stability and cuttings-carrying capability. However, its API fluid loss was not suitable for measurement. This disadvantage could be mitigated through controlling the density of CFMDF-NP to the underbalanced drilling or approximately balanced drilling. Therefore, positive pressure differential would not take place. As a result, it would prevent the fluid loss in the coal seams.

Furthermore, the micromorphology of HV-CFMDFNP observed with metallographic electron microscope was shown in Figure 5. At ambient temperature and atmospheric pressure, microfoamed drilling fluid was in a nonaggregated, noncontinuous, and stable dispersive form. The shape of the bubble was sphere, and its diameter mainly ranged from 30 to $200 \mu \mathrm{m}$. As mentioned above, the diameter of the bubble depended on not only the formula of the foamed drilling fluid but also the mixing conditions such as mixing speed and mixing time. Therefore, the bubble size could be controlled to match with the width or the diameter of the coal cleats or fractures and realize ideal sealing performance. Bubble groups might be suspended in a single and partially interconnected way in the system, and foam stability mainly depended on the film strength and continuous phase together to achieve specific performance [32]. The plateau boundary with point contact of microbubbles was not observed and the foam stability worked well.

3.4. Swelling Test. In the swelling test, the man-made coal cores in contact with fresh water underwent the highest swelling increment $(0.45 \mathrm{~mm}$ for 6 hours, as shown in Figure 6), indicating that the commonly used fresh water could cause the serious hydration of the man-made coal core and bring formation damage to CBM reservoirs with a high clay mineral content. It was confirmed that $\mathrm{KCl}$ was an inorganic inhibitor for clay hydration. Its 3\% solution still experienced a swelling amount of $0.28 \mathrm{~mm}$ for 6 hours. Commonly used bentonite mud showed better inhibitive performance than $3 \% \mathrm{KCl}$ solution. The $\mathrm{HV}$-CFMDF-NP was observed with the lowest swelling increment (only $0.01 \mathrm{~mm}$ for 6 hours), indicating that it could effectively seal the natural cleats and the tectonic fractures and plug the nanosized pores of the coal core; therefore it could decrease the invasion of particles and filtration.

3.5. Gas Permeability Appraisal. Table 4 and Figure 7 presented the gas $\left(\mathrm{N}_{2}\right)$ permeability test results of original coal cores. With the JHGP intelligent gas permeability tester, the coal cores numbered with 1-3\# had an average original gas permeability of $8.26 \mathrm{mD}, 5.43 \mathrm{mD}$, and $2.28 \mathrm{mD}$, respectively. After being contaminated by the HV-CFMDF-NP at $2 \mathrm{MPa}$ confining pressure and $1 \mathrm{MPa}$ axle pressure for 2 hours in the JHCF core flowing tester, no leakage at the other side of the coal core was observed. The contaminated coal cores' average gas permeability decreased to $2.25 \mathrm{mD}, 2.71 \mathrm{mD}$, and $1.35 \mathrm{mD}$, with a decreasing rate of $72.77 \%, 50.08 \%$, and $40.72 \%$, respectively. It indicated that the HV-CFMDF-NP could effectively seal the natural cleats, tectonic fractures, and nanosized pores of coal cores.

It also observed that the higher the original gas permeability of coal cores, the higher the decreasing ratio of gas permeability. It could be explained that higher gas permeability of coal core represented more DFD particles; LV-PAC and foam could plug and seal the cleats, fractures, and micropores of coal cores. Furthermore, the filtrate from the drilling fluid could invade the deeper space of coal cores.

After the contaminated side of coal cores was sliced by $5-$ $8 \mathrm{~mm}$, the recovered average gas permeability was $7.07 \mathrm{mD}$, $4.16 \mathrm{mD}$, and $1.96 \mathrm{mD}$, with the average recovery rate was $85.63 \%, 76.68 \%$ and $85.97 \%$, respectively. It meant that the contaminated depth of the HV-CFMDF-NP to coal core was relatively shallow and it could be easily removed by frequently used perforation or hydraulic fracturing technology in oil and gas industry.

To get better comparison effect, $3 \% \mathrm{KCl}$ solution was evaluated upon coal cores numbered with 6-7\#. These two coal cores had an average original gas permeability of $10.46 \mathrm{mD}$ and $2.79 \mathrm{mD}$, respectively. After being contaminated by $3 \%$ $\mathrm{KCl}$ solution in the JHCF core flowing tester, the average gas permeability of the coal cores decreased to $5.66 \mathrm{mD}$ and $1.37 \mathrm{mD}$, with a decreasing rate of $45.89 \%$ and $50.90 \%$, respectively. It is well known that $\mathrm{KCl}$ was a commonly used inorganic inhibitor. However, it still caused serious formation damage to original coal cores. This phenomenon highlighted the importance of low damage drilling fluid such as the CFMDF-NP. Moreover, obvious leakage of filtrate from the other side of core flowing tester was recorded as $7.68 \mathrm{~mL}$ and $0.2 \mathrm{~mL}$, respectively. It meant that the coal cores were totally contaminated by $\mathrm{KCl}$ solution. It meant even the method of slicing or hydraulic fracturing could not remove the formation damage. 


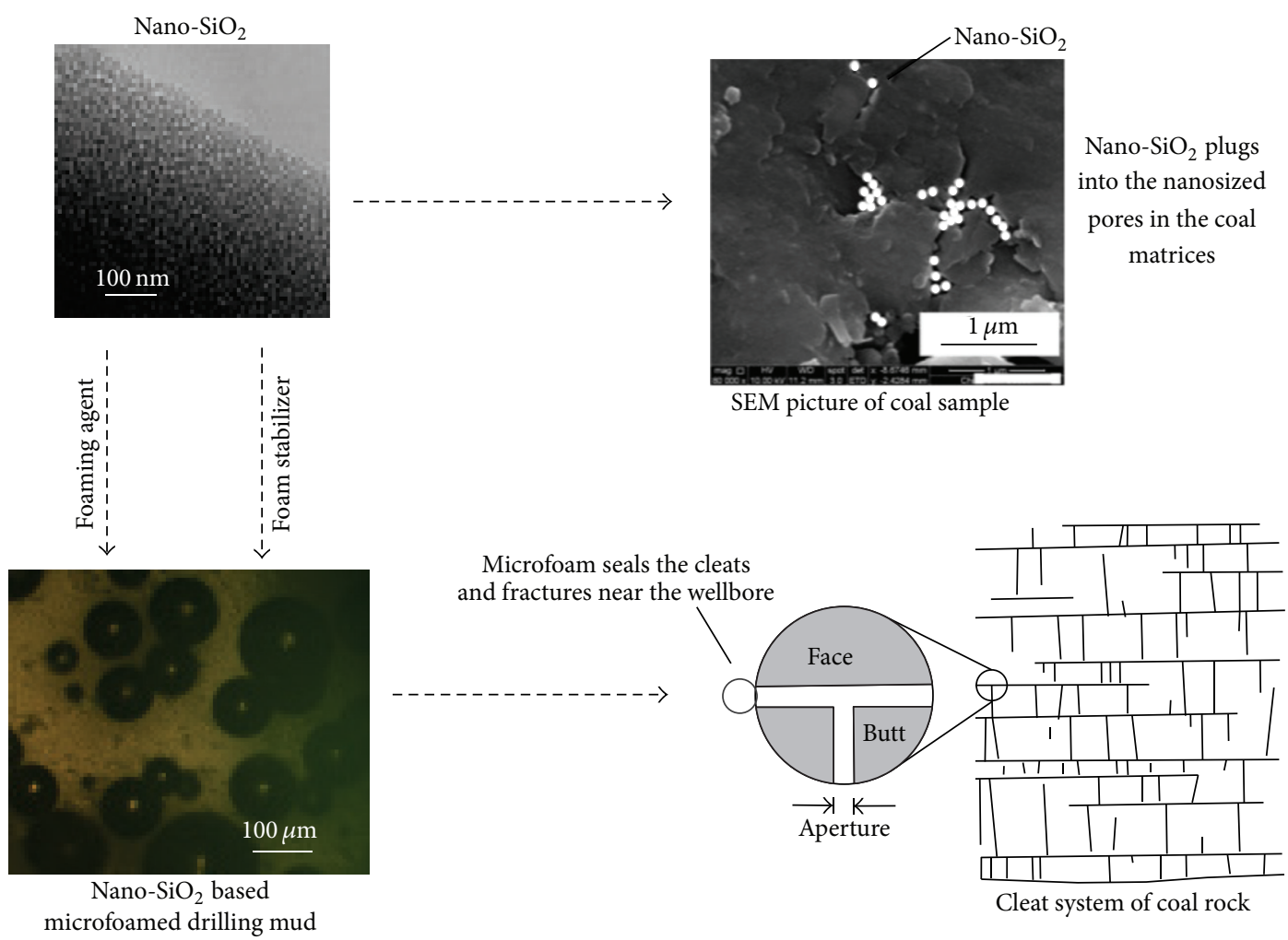

FIGURE 8: Function mechanism of the clay free microfoamed drilling fluid stabilized by nano-SiO ${ }_{2}(\mathrm{CFMDF}-\mathrm{NP})$.

\subsection{Mechanism of Microfoamed Drilling Fluid Stabilized by} Nano- $-\mathrm{SiO}_{2}$. Through a series of tests above, the clay free microfoamed drilling fluid stabilized by nano- $\mathrm{SiO}_{2}$ (CFMDFNP) showed excellent basic performance, good inhibitive capability, and low formation damage characteristic to coal rocks compared with the commonly used fresh water, bentonite mud, and $3 \% \mathrm{KCl}$ solution in $\mathrm{CBM}$ drilling.

\subsubsection{Function Mechanism of Nano-SiO ${ }_{2}$ in Microfoamed} Drilling Fluid. Solid nanoparticles have been shown to permanently stabilize foams by assembling into layers at the gas/water interface. Binks and Horozov [33] demonstrated that foams (gas/water dispersions) could be generated and stabilized by silica nanoparticles without the need of surfactant. At proper sodium dodecyl sulfate concentrations, the surfactant molecules induced the $\mathrm{SiO}_{2}$ particles to move to the interface and changed the structure of the surface layer [34]. The enhanced stability may be attributed to enhanced structural forces [35] and a large desorption energy of the particles from the interface [36]. Nanoparticle-stabilized foam is very stable because it needs more energy to get to or leave bubble surface than conventional surfactants; therefore the foamed drilling fluid with nano- $\mathrm{SiO}_{2}$ has better stability [37, 38]. Furthermore, it was thought that the solid particle layers of particle stabilized foams might have similar solid-like properties when compressed [39]. On the other side, nano- $\mathrm{SiO}_{2}$ had high surface activity which might bring higher foaming volume to foamed drilling fluid.
On the other hand, it is well known that the pore diameter of gas shales in China and North America is in a range of 5-300 nm and $8-100 \mathrm{~nm}$ separately [40-45]. Therefore, the plugging mechanism of nano- $\mathrm{SiO}_{2}$ acting on shales may be fit for coal rock. The plugging of nano- $\mathrm{SiO}_{2}$ into shale had been confirmed by Sensoy et al. [46] carrying out the scanning electron microscope tests on the Atoka shale in contact with $20 \mathrm{~nm}$ nano- $\mathrm{SiO}_{2}$. It is difficult for nano- $\mathrm{SiO}_{2}$ to plug all the pore throats; however, the average pore throats would decrease with the plugging of nano- $\mathrm{SiO}_{2}$ into the pore throats, which would increase the capillary force and restrict the further invading of drilling fluids. On the other side, the sealing zone formed by nano- $\mathrm{SiO}_{2}$ is beneficial to form thinner mud cake and lower fluid loss of drilling fluid. As a whole, physical plugging of nano-SiO ${ }_{2}$ can block the nanosized pore throats, restrict the transmission of pore pressure, and therefore improve wellbore stability [47].

\subsubsection{Mechanism of Microfoamed Drilling Fluid Stabilized} by $\mathrm{Nano}-\mathrm{SiO}_{2}$. The mechanism of the CFMDF-NP can be illustrated as follows, as shown in Figure 8.

The CFMDF-NP had the controllable density (0.7$1.0 \mathrm{~g} / \mathrm{cm}^{3}$ ) which could be adapted to the low pressure characteristics of coal seams in China. In underbalanced drilling condition, the filtrate and particles of the drilling fluid could not invade into the reservoir and therefore the formation damage caused by drilling fluid could be avoided. It also had adjustable rheological properties to ensure borehole stability and cuttings transporting. Its bubble size was also 
controllable by the selection of drilling fluid formula or mixing conditions to match with the width of the cleats or fractures.

Ever under some circumstances where a positive pressure differential exists, the formation damage could be minimized by complex methods as follows. The elastic bubble (30$200 \mu \mathrm{m}$ ) in the CFMDF-NP could adsorb and seal the natural cleats and tectonic fractures of coal rocks (Figure 8). It was acknowledged that once the nanosized pores formed in the matrix of the coal rock adsorbed water or filtration, the pore volume would reduce and restrict the desorption of methane from the nanosized pores to the cleats, resulting in formation damage. Fortunately, the $10-20 \mathrm{~nm}$ nano- $\mathrm{SiO}_{2}$ in the CFMDF-NP could be temporally plugged into the nanosized pores with one or several particles' accumulation, as shown in Figure 8. With the synergism of elastic bubble's sealing into the cleats and fractures plus the plugging of nano$\mathrm{SiO}_{2}$ into the nanosized pores, the invasion of particles and filtrate of drilling fluid into the coal rocks near the borehole could be minimized and therefore decrease the formation damage.

Moreover, the temporally contaminated zone around the borehole could be easily removed by the frequent perforation or hydraulic fracturing technology.

\section{Conclusions}

(1) In presence of nano- $\mathrm{SiO}_{2}$ with the diameter from 10 to $20 \mathrm{~nm}$, the stability of foamed drilling fluid could be improved by up to $50 \%$ whose half-value period could be prolonged by up to $200 \%$. Unlike conventional foam stabilizers, nano- $\mathrm{SiO}_{2}$ functions as not only a foam stabilizer but also a foaming agent. To nanoparticles like nano- $\mathrm{SiO}_{2}$, it needed more energy to reach or leave the bubble surface than conventional surfactants, leading to better stability of the foam drilling fluid.

(2) The geology pattern of CBM reservoirs in China makes the clay free microfoamed drilling fluid stabilized by nano- $\mathrm{SiO}_{2}$ (CFMDF-NP) as required. It has controllable density $\left(0.7-1 \mathrm{~g} / \mathrm{cm}^{3}\right)$ which is easy to realize underbalanced drilling and therefore avoid particles and filtrate invasion into the coal rocks and further prevent formation damage. Its rheological performances can increase borehole stability and benefit solids transport capability.

(3) Even under a positive pressure differential, with the synergism of elastic bubble's sealing into the natural cleats and tectonic fractures plus the plugging of nano- $\mathrm{SiO}_{2}$ into the nanosized pores, the invasion of particles and filtrate of drilling fluid into the coal rocks around the borehole could be minimized and therefore decrease the formation damage. The adjustable bubble size of the CFMDF-NP makes it possible to seal differently sized cleats and fractures perfectly.

(4) With 5-8 $\mathrm{mm}$ slicing, the recovery rate of gas permeability of coal rocks in contact with the CFMDF-NP reached up to $70 \%$, which is far superior to the commonly used fresh water, bentonite mud and $\mathrm{KCl}$ solution. The temporally formed zone around the borehole could be easily removed by the frequent perforation or hydraulic fracturing technology.

\section{Conflict of Interests}

The authors declare that there is no conflict of interests regarding the publication of this paper.

\section{Acknowledgments}

The work was financially supported by the National Science Foundation of China (no. 41072111), the CNPC Innovation Foundation (no. 2014D-5006-0308), the Key Project of Natural Science Foundation of Hubei Province (no. 2015CFA135), and the Special Fund for Basic Scientific Research of Central Colleges (no. CUG130612).

\section{References}

[1] Y. D. Cai, D. M. Liu, Z. J. Pan, Y. B. Yao, J. Q. Li, and Y. K. Qiu, "Pore structure and its impact on $\mathrm{CH}_{4}$ adsorption capacity and flow capability of bituminous and subbituminous coals from Northeast China," Fuel, vol. 103, pp. 258-268, 2013.

[2] J. N. Pan, H. T. Zhu, Q. L. Hou, H. C. Wang, and S. Wang, "Macromolecular and pore structures of Chinese tectonically deformed coal studied by atomic force microscopy," Fuel, vol. 139, pp. 94-101, 2015.

[3] R. Sakurovs, L. L. He, Y. B. Melnichenko et al., "Pore size distribution and accessible pore size distribution in bituminous coals," International Journal of Coal Geology, vol. 100, pp. 51-64, 2012.

[4] H. Gan, P. L. Walker Jr., and S. P. Nandi, "Nature of the porosity in American coals," Fuel, vol. 51, no. 4, pp. 272-277, 1972.

[5] J. Rouquerol, D. Avnir, C. Fairbridge et al., "Recommendations for the characterization of porous solids (Technical Report)," Pure and Applied Chemistry, vol. 66, no. 8, pp. 1739-1758, 1994.

[6] C. R. Clarkson and R. M. Bustin, "Variation in micropore capacity and size distribution with composition in bituminous coal of the Western Canadian Sedimentary Basin: implications for coalbed methane potential," Fuel, vol. 75, no. 13, pp. 1483$1498,1996$.

[7] H. H. Liu, J. H. Mou, and Y. P. Cheng, "Impact of pore structure on gas adsorption and diffusion dynamics for long-flame coal," Journal of Natural Gas Science and Engineering, vol. 22, pp. 203213, 2015.

[8] S.-Q. Liu, S.-X. Sang, H.-H. Liu, and Q.-P. Zhu, "Growth characteristics and genetic types of pores and fractures in a high-rank coal reservoir of the southern Qinshui basin," Ore Geology Reviews, vol. 64, pp. 140-151, 2015.

[9] Y. Song, X. M. Zhang, and S. B. Liu, Basic Theories of Coalbed Methane Geology and Development in China, Scientific Press, Beijing, China, 2012.

[10] Y. B. Yao, D. M. Liu, D. Z. Tang et al., "Fractal characterization of seepage-pores of coals from China: an investigation on permeability of coals," Computers and Geosciences, vol. 35, no. 6, pp. 1159-1166, 2009.

[11] Y. B. Yao and D. Liu, "Effects of igneous intrusions on coal petrology, pore-fracture and coalbed methane characteristics in Hongyang, Handan and Huaibei coalfields, North China," International Journal of Coal Geology, vol. 96-97, pp. 72-81, 2012.

[12] Q. B. Zhao, W. Z. Li, B. Sun et al., Geology and Exploration Technologies of Coalbed Methane, Petroleum Industry Press, Beijing, China, 1999. 
[13] X. M. Ni, X. B. Su, and X. D. Zhang, Coal Bed Methane Development Geology, Chemical Industry Press, Beijing, China, 2010.

[14] K. H. Cui and H. T. Zheng, Coalbed Methane Exploitation, Petroleum Industry Press, Beijing, China, 2009.

[15] C. Ö. Karacan, F. A. Ruiz, M. Cotè, and S. Phipps, "Coal mine methane: a review of capture and utilization practices with benefits to mining safety and to greenhouse gas reduction," International Journal of Coal Geology, vol. 86, no. 2-3, pp. 121156, 2011.

[16] L. V. Baltoiu, B. K. Warren, and T. A. Natros, "State-of-the-art in coalbed methane drilling fluids," SPE Drilling \& Completion, vol. 23, no. 3, pp. 250-257, 2008.

[17] K. L. Barr, "A guideline to optimize drilling fluids for coalbed methane reservoirs," in Proceedings of the SPE Rocky Mountain Petroleum Technology Conference, SPE 123175, Denver, Colo, USA, April 2009.

[18] J.-H. Cai, H. Liu, Y. Chen, and C.-B. Xiao, "Study on degradable drilling fluid system for coalbed methane horizontal drilling," Journal of the China Coal Society, vol. 36, no. 10, pp. 1683-1688, 2011.

[19] J.-H. Cai, J.-J. Wang, Y. Yuan, and H. Liu, "Inhibitive ability appraisal of salt solution on coal rock," Journal of the China Coal Society, vol. 37, no. 6, pp. 951-956, 2012.

[20] W.-A. Huang, Z.-S. Qiu, Y.-Q. Wang et al., "Study on damage mechanism and protection drilling fluid for coalbed methane," Journal of the China Coal Society, vol. 37, no. 10, pp. 1717-1721, 2012.

[21] T. Gentzis, N. Deisman, and R. J. Chalaturnyk, "Effect of drilling fluids on coal permeability: impact on horizontal wellbore stability," International Journal of Coal Geology, vol. 78, no. 3, pp. 177-191, 2009.

[22] Y. Qin, L. Yuan, Q. T. Hu et al., "Status and development orientation coal bed methane exploration and development technology in China," Coal Science and Technology, vol. 40, no. 10, pp. 1-6, 2012.

[23] L. H. Zheng, L. C. Kong, Y. Cao, H. Y. Wang, Z. X. Han, and X. Q. He, "The mechanism for fuzzy-ball working fluids for controlling \& killing lost circulation," Chinese Science Bulletin, vol. 55, no. 35, pp. 4074-4082, 2010.

[24] S. Akhtarmanesh, M. J. A. Shahrabi, and A. Atashnezhad, "Improvement of wellbore stability in shale using nanoparticles," Journal of Petroleum Science and Engineering, vol. 112, pp. 290-295, 2013.

[25] J. H. Cai, M. E. Chenevert, M. M. Sharma, and J. Friedheim, "Decreasing water invasion into Atoka shale using nonmodified silica nanoparticles," SPE Drilling and Completion, vol. 27, no. 1, pp. 103-112, 2012.

[26] M. M. Sharma, R. Zhang, M. E. Chenevert, L. Ji, Q. Guo, and J. Friedheim, "A new family of nanoparticle based drilling fluids," in Proceedings of the SPE Annual Technical Conference and Exhibition, SPE-160045-MS, Society of Petroleum Engineers, San Antonio, Tex, USA, October 2012.

[27] N. W. Bentsen and J. N. Veny, "Preformed stable foam performance in drilling and evaluating shallow gas wells in Alberta," Journal of Petroleum Technology, vol. 28, no. 10, pp. 1237-1240, 1976.

[28] R. L. Essary and E. E. Rogers, "Techniques and results of foam redrilling operations-San Joaquin Valley, California," in Proceedings of the SPE Symposium on Formation Damage Control, SPE 5715, Society of Petroleum Engineers, Houston, Tex, USA, January 1976.
[29] D. L. Hall and R. D. Roberts, "Offshore drilling with preformed stable foam," in Proceedings of the SPE California Regional Meeting, SPE-12794-MS, Society of Petroleum Engineers, Long Beach, Calif, USA, April 1984.

[30] X.-M. Li and X.-L. Pu, "Study of recyclable micro-foam drilling fluid," Journal of Southwest Petroleum Institute, vol. 24, no. 6, pp. 53-56, 2002 (Chinese).

[31] Z. Chen, Cuttings Transport with foam in horizontal concentric annulus under elevated pressure and temperature conditions [dissertation thesis], University of Tulsa, 2005.

[32] Z. H. Zhang, "Preparation and application of circulative microfoamed drilling fluid," Acta Petrolei Sinica, vol. 25, no. 6, pp. 9295, 2014.

[33] B. P. Binks and T. S. Horozov, "Aqueous foams stabilized solely by silica nanoparticles," Angewandte Chemie-International Edition, vol. 44, no. 24, pp. 3722-3725, 2005.

[34] Q. Sun, Z. Li, J. Wang et al., "Aqueous foam stabilized by partially hydrophobic nanoparticles in the presence of surfactant," Colloids and Surfaces A: Physicochemical and Engineering Aspects, vol. 471, pp. 54-64, 2015.

[35] A. D. Nikolov and D. T. Wasan, "Dispersion stability due to structural contributions to the particle interaction as probed by thin liquid film dynamics," Langmuir, vol. 8, no. 12, pp. 29852994, 1992.

[36] S. Tcholakova, N. D. Denkov, and A. Lips, "Comparison of solid particles, globular proteins and surfactants as emulsifiers," Physical Chemistry Chemical Physics, vol. 10, no. 12, pp. 16081627, 2008.

[37] D. R. Espinosa, Nanoparticle-stabilized supercritical $\mathrm{CO}_{2}$ foams for potential mobility control applications [Ph.D. dissertation], University of Texas at Austin, Austin, Tex, USA, 2011.

[38] A. Aroonsri, Nanoparticle-stabilized $\mathrm{CO}_{2}$ foam for mobility control in $\mathrm{CO}_{2}$ enhanced oil recovery [Ph.D. thesis], University of Texas at Austin, Austin, Tex, USA, 2014.

[39] R. F. Salas Porras, Compressibility of nanoparticle stabilized foams for foamed cement applications [Ph.D. thesis], University of Texas at Austin, 2014.

[40] P. H. Nelson, "Pore-throat sizes in sandstones, tight sandstones, and shales," AAPG Bulletin, vol. 93, no. 3, pp. 329-340, 2009.

[41] R. J. Ambrose, R. C. Hartman, M. D. Campos, I. Y. Akkutlu, and C. Sondergeld, "New pore-scale considerations for shale gas in place calculations," in Proceedings of the SPE Unconventional Gas Conference, SPE 131772, Society of Petroleum Engineers, Pittsburgh, Pa, USA, February 2010.

[42] M. Milner, R. McLin, and J. Petriello, "Imaging texture and porosity in mudstones and shales: comparison of secondary and ion-milled backscatter SEM methods," in Proceedings of the Canadian Unconventional Resources and International Petroleum Conference, SPE 138975, Calgary, Canada, October 2010.

[43] J. Schieber, "Common themes in the formation and preservation of intrinsic porosity in shales and mudstones-illustrated with examples across the Phanerozoic," in Proceedings of the SPE Unconventional Gas Conference, SPE 132370, Society of Petroleum Engineers, Pittsburgh, Pa, USA, February 2010.

[44] C. H. Sondergeld, R. J. Ambrose, C. S. Rai, and J. Moncrieff, "Micro-structural studies of gas shales," in Proceedings of the SPE Unconventional Gas Conference, SPE 131771, Society of Petroleum Engineers, Pittsburgh, Pa, USA, February 2010.

[45] Z. Caineng, Z. Rukai, B. Bin et al., "First discovery of nano-pore throat in oil and gas reservoir in China and its scientific value," Acta Petrologica Sinica, vol. 27, no. 6, pp. 1857-1864, 1857. 
[46] T. Sensoy, M. E. Chenevert, and M. M. Sharma, "Minimizing water invasion in shales using nanoparticles," in Proceedings of the SPE Annual Technical Conference and Exhibition, SPE 124429, Society of Petroleum Engineers, New Orleans, La, USA, October 2009.

[47] X.-Y. Yang, Y. Yue, J.-H. Cai, Y. Liu, and X.-M. Wu, "Experimental study and stabilization mechanisms of silica nanoparticles based brine mud with high temperature resistance for horizontal shale gas wells," Journal of Nanomaterials, vol. 2015, Article ID 745312, 9 pages, 2015. 

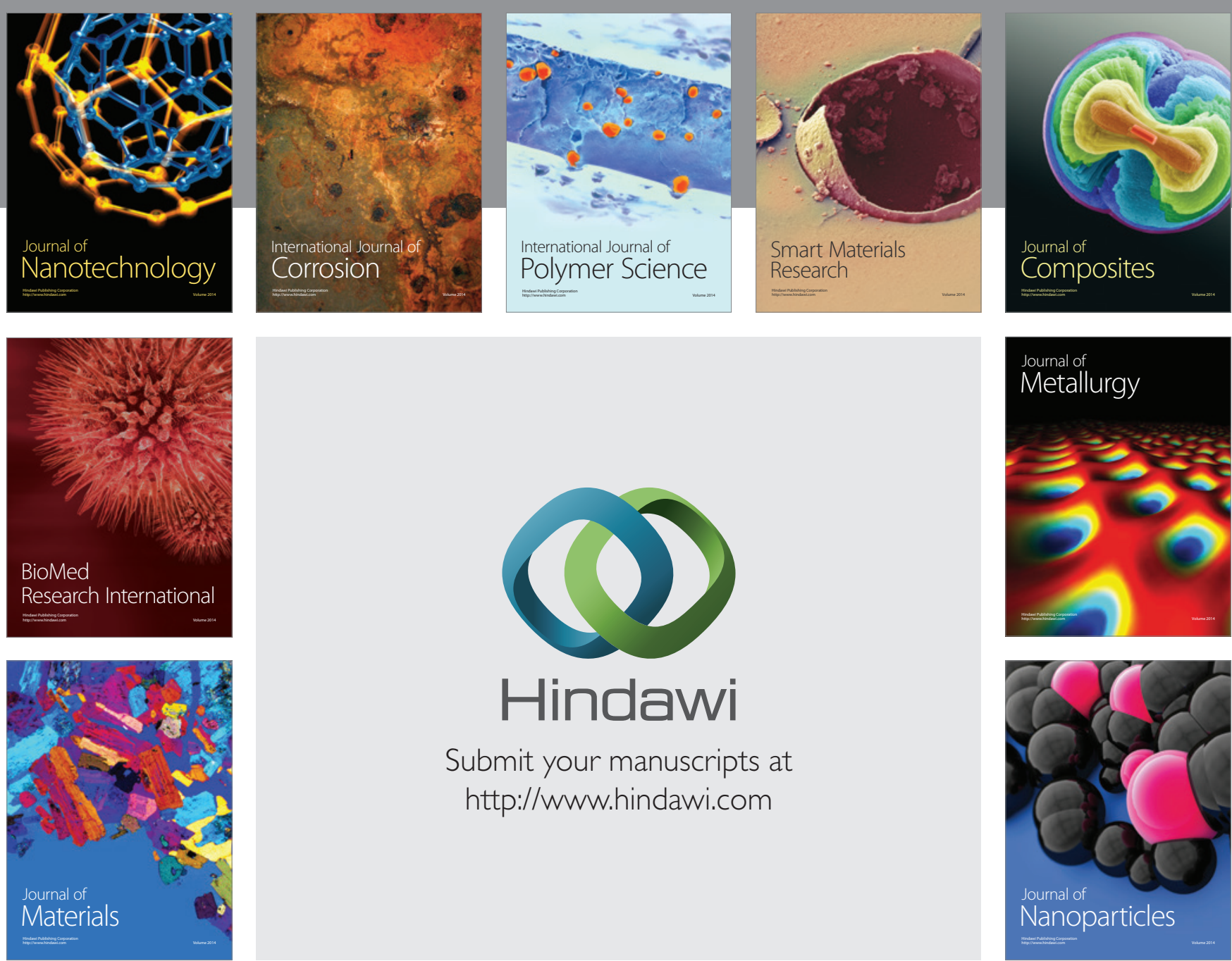

\section{Hindawi}

Submit your manuscripts at

http://www.hindawi.com

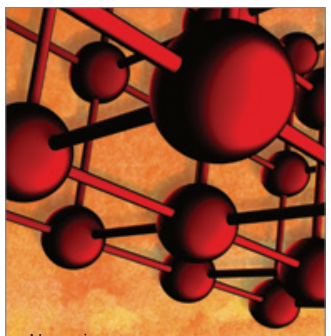

Materials Science and Engineering
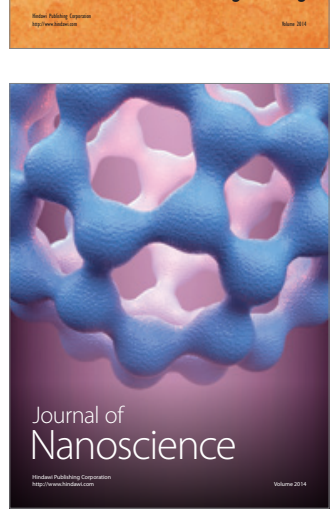
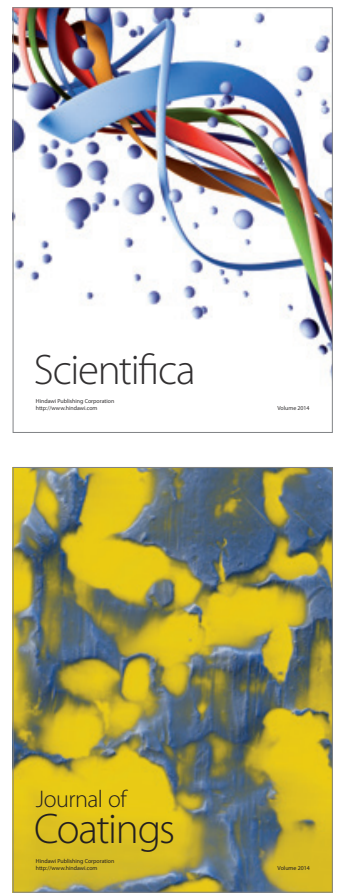
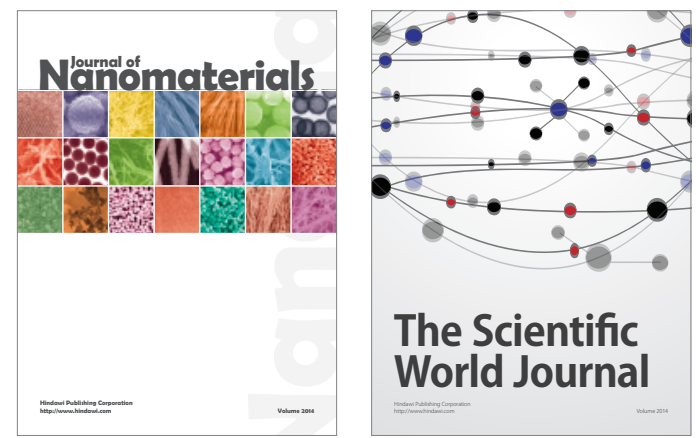

The Scientific World Journal
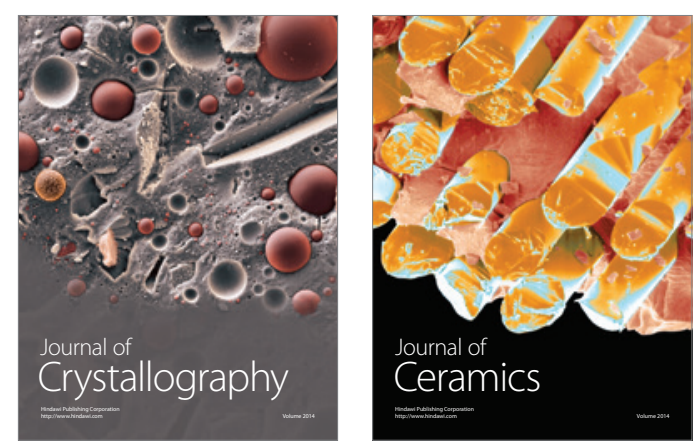
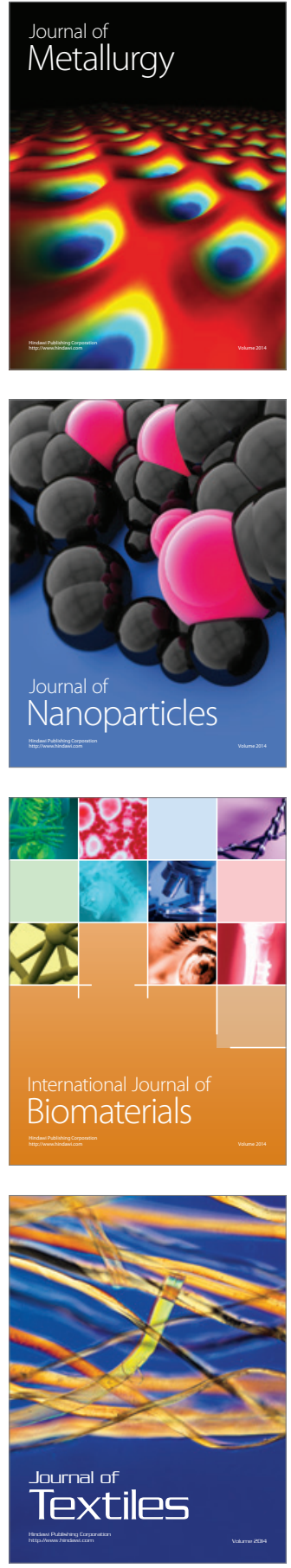